\title{
EXPERIMENTAL STUDY ON DYNAMIC WELDING OF AgW60, CuW60 AND Cu CONTACT MATERIALS IN SYMMETRICAL AND ASYMMETRIC PAIRINGS AT DC $270 \mathrm{~V} / 200 \mathrm{~A}$
}

\author{
Liao $\mathrm{YuAn}^{a}, \mathrm{Zhang}_{\mathrm{Dandan}}{ }^{a}, \mathrm{He} \mathrm{MengBing}^{a}$, Makoto Hasegawa $^{b}$, \\ Li ZHENBIAO ${ }^{a, *}$ \\ ${ }^{a}$ State Key Laboratory of Advanced Electromagnetic Engineering and Technology, School of Electrical and \\ Electronic Engineering, Huazhong University of Science and Technology, Wuhan 430074, China \\ ${ }^{b}$ Chitose Institute of Science and Technology, Chitose, Hokkaido, 066-8655, Japan \\ * zbli@hust.edu.cn
}

\begin{abstract}
Experiments were conducted for AgW60, CuW60 and $\mathrm{Cu}$ contacts and their different pairings at DC $270 \mathrm{~V} / 200 \mathrm{~A}$ in a surrounding atmosphere of carbon dioxide or nitrogen. Welding resistances, average welding forces and relationships between welding forces and the number of operations required for welding were measured and analyzed. The anti-welding ability of the three materials in their symmetric pairings in carbon dioxide and nitrogen can be ranked as $\mathrm{AgW} 60>\mathrm{Cu}>\mathrm{CuW} 60$. The "intermediate effect" occurs in the anti-welding properties of the asymmetric pairings. The relationships between the number of operations required for welding and the average welding force is approximately in an inverse proportional function.
\end{abstract}

Keywords: surrounding atmosphere, contact material, DC, welding, welding force, AgW60, CuW60, $\mathrm{Cu}$.

\section{Introduction}

Switching capabilities in large DC load conditions while realizing miniaturization and long life are strongly required for switching devices such as relays and contactors [1]. For example, solar power generation facilities and energy storage batteries becomes popular increase year by year, leading to larger demands for high voltage/current switches. Relay contacts are subjected to heavier loads more and more, and their failures are sometimes inevitable. Dynamic welding is one of the most serious failures. With high voltage/current levels, different contact materials and ambient atmospheres have important influences on anti-welding abilities of contacts for improving reliabilities and electrical life of miniaturized high voltage/current relays. However, at present, there are few experimental studies on effects of different contact materials and their matching forums as well as ambient atmospheres on welding characteristics of DC contacts.

In this paper, dynamic welding characteristics were studied and analyzed with AgW60, CuW60 and $\mathrm{Cu}$ contacts under DC resistive $270 \mathrm{~V} / 200 \mathrm{~A}$ in carbon dioxide or nitrogen with 9 kinds of symmetrical and asymmetrical material pairings.

\section{Experimental method}

Fig.1 shows a schematic diagram of the experimental circuit in this study. The main circuit included a DC regulated power source $\mathrm{E}$ providing an output voltage of $270 \mathrm{~V}$, a load resistor $\mathrm{R}$ of $1.35 \Omega$, and a pair of electrical contacts $\mathrm{K}$ which was set on the simulation test device. The voltage $U_{N}$ between the pair of contacts $\mathrm{K}$ was measured with a voltage divider 1, while the voltage $U_{M}$ was measured with another voltage divider 2 .

A schematic diagram of the electrical contact simulation device $\mathrm{K}$ is shown in Figure 2. The contacts are normally closed, and the electromagnet provides a breaking force, while the spring provides a closing force. A force sensor is connected to one side of the static contact. At each contact operation, the welding will be cooled and solidified after the material is melted, resulting in a different degree of welding. The breaking force at the moment of separation of the two contact surfaces in the breaking operation is taken as the welding force $F_{W}$ of that time.

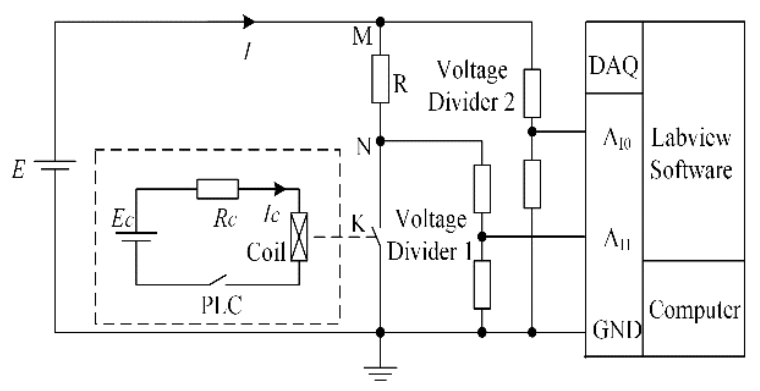

Figure 1. A schematic diagram of the experimental circuit.

AgW60, CuW60 and $\mathrm{Cu}$ contact materials were studied. One make-and-break operation was set as $0.7 \mathrm{~s}$ ON and $2.3 \mathrm{~s}$ OFF. Under the experimental conditions, because the division strategy is relatively high, 
the setting is the contact turn-on time is much shorter than the break-off time, which can ensure more operation times and facilitate the study of various electrical properties of the contacts. Magnetic blow-out was created at the magnetic flux density of $110 \mathrm{mT}$ with a pair of magnets. Before the experiment, the contact simulation device was placed in a vacuum simulation chamber as a whole, and carbon dioxide or nitrogen gas with a pressure of $1 \times 10^{5} \mathrm{~Pa}$ was charged. The two samples $1 \#$ and $2 \#$ were tested for each pair of contacts in both carbon dioxide and nitrogen. In the experiment, when the first welding occurred, the electrodes were manually disconnected and the experiment was resumed up to the third welding incidence. For the convenience of description, the number of operations required for each of the three welding incidences were recorded as $N_{1}, N_{2}$, and $N_{3}$, respectively (each counting was started from 1).

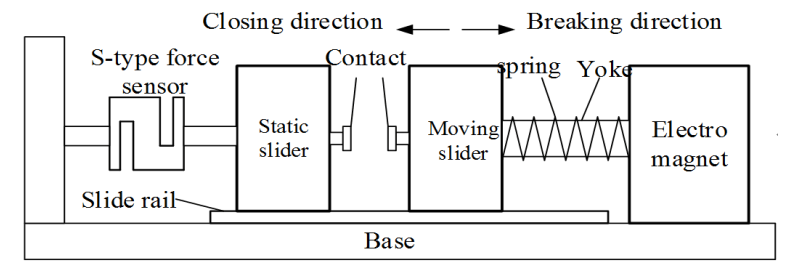

Figure 2. Electrical contacting simulator.

\section{Experimental results and analysis}

\subsection{Contact welding resistance}

Welding resistance of contacts is defined by the number of operations when welding occurs for the first time. The larger the number of operations for the first welding, the higher the welding resistance of contacts. In this study, the average number of operations $\bar{N}_{1}$ for the results of the two samples $1 \#$ and $2 \#$ is used to determine the welding resistance capability. The calculation formula of $\bar{N}_{1}$ is:

$$
\bar{N}_{1}=\left(N_{1}(1)+N_{1}(2)\right) / 2
$$

where $N_{1}(j)(j=1,2)$ is the number of operations when the $j$-th sample of contact pairs is first welded.

Tables 1 and 2 show the results of the average first welding values $\bar{N}_{1}$. The higher the value of $\bar{N}_{1}$, the higher the welding resistance capability. The welding resistance capabilities in carbon dioxide and nitrogen are not significantly different from each other, while the contact materials have strong influences. For example, AgW60 and CuW60 have smaller values of $\bar{N}_{1}$ in nitrogen than in carbon dioxide, which means their welding resistance in nitrogen is lower than that in carbon dioxide. However, $\mathrm{Cu}$ shows the opposite tendency. The order of the welding resistances of these materials in symmetric pairings in carbon dioxide and nitrogen is: $\mathrm{AgW60}>\mathrm{Cu}>\mathrm{CuW60}$.

The welding resistance capabilities in the asymmetric pairings in carbon dioxide and nitrogen are mostly "intermediate effect". Specifically, when the materials A and B are asymmetrically paired, their welding resistance (corresponding to the number of operations during the first fusion welding, recorded as $N_{A-B}$ ) is between the anti-welding abilities of the symmetrical pairings (recorded as $N_{A-A}, N_{B-B}$ ) where $A-A$ or $B-B$ indicates symmetrical pair (i.e., $N_{A-A}>N_{A-B}>N_{B-B}$ ). In the total of twelve asymmetric pairs in carbon dioxide and nitrogen, the "worst effect" $\left(N_{A-B}<N_{A-A}, N_{A-B}<N_{B-B}\right)$ and "optimal effect" $\left(N_{A-B}>N_{A-A}, N_{A-B}>N_{B-B}\right.$ occur only once. The specific results are shown in Table 3.

\begin{tabular}{lllll}
\hline \hline Anode(+) & Cathode(-) & AgW60 & CuW60 & Cu \\
\cline { 1 - 3 } AgW60 & 1262 & 57 & 100 \\
CuW60 & 142 & 6 & 113 \\
$\mathrm{Cu}$ & 29 & 9 & 27 \\
\hline \hline
\end{tabular}

Table 1. The average first welding $\bar{N}_{1}$ value of contact material in carbon dioxide.

\begin{tabular}{lllll}
\hline \hline Anode(+) & Cathode(-) & \multirow{2}{*}{ AgW60 } & CuW60 & Cu \\
\cline { 1 - 3 } AgW60 & 428 & 15 & 249 \\
CuW60 & 4 & 2 & 59 \\
$\mathrm{Cu}$ & 22 & 5 & 153 \\
\hline \hline
\end{tabular}

Table 2. The average first welding $\bar{N}_{1}$ value of contact material in nitrogen.

According to the following formula, the number of operations $\bar{N}_{k}$ required for each welding in the carbon dioxide and nitrogen can be calculated:

$$
\bar{N}_{k}=\left(N_{3}(1)+N_{3}(2)\right) / 6
$$

$\bar{N}_{3}(j)(j=1,2)$ is the number of operations for the third welding incidence of the $j$-th sample. Table 4 shows the obtained results for $\bar{N}_{k}$.

Comparing Table 4 with Tables 1 and 2, it can be seen that as the number of operations increases, the number of operations between the consecutive welding incidences is reduced, indicating weaker welding resistance. In Table 4, the number of operations required for each welding in carbon dioxide and nitrogen is obtained by diving the number of operations in the third welding by 3 . Among the 18 sets of values, 15 sets shows a smaller value than the first welding.

\subsection{Average welding force of contacts}

The average value of the welding force of all the breaking operations before the first welding was recorded as $\bar{F}_{w 1}$ Table 5 and Table 6 show their results in carbon dioxide and nitrogen, respectively. The similar average welding force value of all the effective operations up to the third welding can be called as the total average welding force, and recorded as $\bar{F}_{w}$. Tables 7 and 8 show their results in carbon dioxide and nitrogen, respectively. 


\begin{tabular}{lllll}
\hline \hline Gases & Pairing material & Worst effect & Intermediate effect & Optimal effect \\
\hline \multirow{3}{*}{ Carbon dioxide } & $\mathrm{AgW60}, \mathrm{CuW60}$ & & $\mathrm{AgW60}(+) \& \mathrm{CuW60}(+)$ & \\
& $\mathrm{AgW60}, \mathrm{Cu}$ & & $\mathrm{AgW60}(+) \& \mathrm{Cu}(+)$ & $\mathrm{CuW60}(+)$ \\
& $\mathrm{CuW60}, \mathrm{Cu}$ & & $\mathrm{Cu}(+)$ & \\
\multirow{5}{*}{ Nitrogen } & $\mathrm{AgW60}, \mathrm{CuW60}$ & & $\mathrm{AgW60}(+) \& \mathrm{CuW60}(+)$ & \\
& $\mathrm{AgW60}, \mathrm{Cu}$ & $\mathrm{Cu}(+)$ & $\mathrm{AgW60}(+)$ & \\
& $\mathrm{CuW60, \textrm {Cu }}$ & & $\mathrm{CuW60}(+) \& \mathrm{Cu}(+)$ & \\
\hline \hline
\end{tabular}

Note: The pairing form of each polarity effect is only labeled with the anode material, and the cathode is another material.

Table 3. Three polar effects of anti-welding ability corresponding to asymmetrical mating.

\begin{tabular}{|c|c|c|c|}
\hline & & $\mathrm{CO}_{2}$ & $N_{2}$ \\
\hline \multirow{3}{*}{$\begin{array}{c}\text { Symmetric } \\
\text { pairing }\end{array}$} & $\mathrm{AgW} 60$ & 489 & 190 \\
\hline & $\mathrm{CuW} 60$ & 6 & 4 \\
\hline & $\mathrm{Cu}$ & 20 & 109 \\
\hline \multirow{6}{*}{$\begin{array}{l}\text { Asymmetric } \\
\text { pairing }\end{array}$} & AgW60(+)CuW60(-) & 188 & 12 \\
\hline & AgW60(-)CuW60(+) & 81 & 2 \\
\hline & $\mathrm{AgW} 60(+) \mathrm{Cu}(-)$ & 383 & 115 \\
\hline & $\operatorname{AgW60(-)Cu(+)}$ & 10 & 13 \\
\hline & $\mathrm{CuW60(+)} \mathrm{Cu}(-)$ & 68 & 51 \\
\hline & 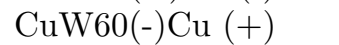 & 9 & 1 \\
\hline
\end{tabular}

Table 4. The value of average number of operations $\bar{N}_{k}$ required for each weld.

Table 9 shows the three polar effects of total average welding force when the contacts are asymmetrically paired in carbon dioxide and nitrogen.

Table 5 - Table 8 shows that as the number of operations increases, the average welding force of the contacts decreases. The three materials in Tables 7 and 8 have a total of 18 pairings, of which the total average welding force of the 16 pairs is lower than the average welding force before the first welding in Tables 5 and 6.

Table 9 shows that in carbon dioxide and nitrogen, the "worst effect", "intermediate effect" and "optimal effect" of the asymmetric average pairing of AgW60, $\mathrm{CuW60}$ and $\mathrm{Cu}$ materials exist.

\subsection{Relationship between welding force and the number of operations during welding}

By correlating the data in Tables 1 and 2 with the data in Tables 5 and 6 , relationships between the average number of operations $\bar{N}_{1}$ in the first welding and the average welding force $\bar{F}_{w 1}$ before the first welding can be shown as in Fig. 3 in log scale. Similarly, by correlating the data in Tables 4 with the data in Tables 6 and 7 , relationships between the average number of operations required for each welding incidence and the total average welding force can be shown as in Fig. 4 in $\log$ scale.

Fig. 3 shows that the larger the average welding force $\bar{F}_{w 1}$ before the first welding, the smaller the average number of operations $\bar{N}_{1}$ in the first welding, and the relationship between them is approximately an inverse proportional function (power function). The fitting relationship in Fig. 4 is $y=28.263 x^{-0.989}$, the goodness of fit $R^{2}=0.8812$.

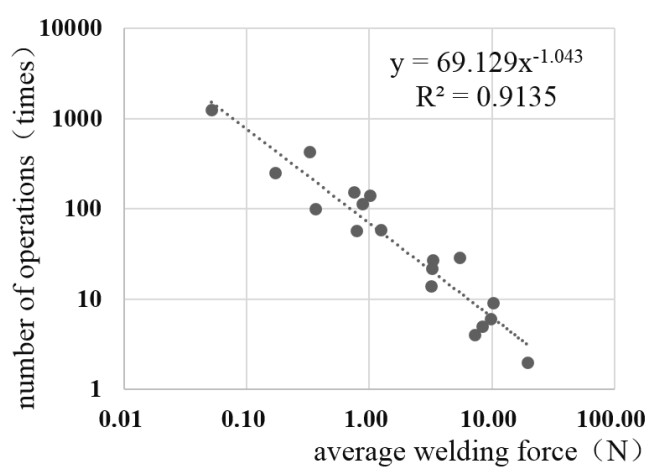

Figure 3. The relationship between $\bar{N}_{1}$ and $\bar{F}_{w 1}$.

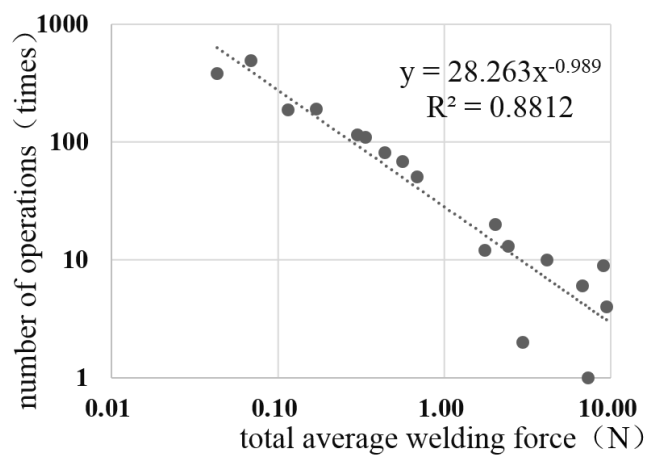

Figure 4. The relationship between $\bar{N}_{k}$ and $\bar{F}_{w}$.

\section{Discussions}

The occurrence of welding during the closing or breaking process of the contact material mainly comprises two processes: Process 1 is a heating process, reflecting the time during which the material per unit area of the contact surface melts after the arc energy is injected, thereby estimating the welding tendency of the contact material. Process 2 is a cooling process that reflects the area of fusion and the amount of welding force. The welding tendency and the welding force of the integrated contact are related to the welding resistance of a certain contact material [2]. In this paper, as the number of operations increases, the average welding force of the contacts decreases, 


\begin{tabular}{lllll}
\hline \hline Gases & Pairing material & Worst effect & Intermediate effect & Optimal effect \\
\hline \multirow{3}{*}{ Carbon dioxide } & $\mathrm{AgW60}, \mathrm{CuW60}$ & & $\mathrm{AgW60}(+) \& \mathrm{CuW60}(+)$ & \\
& $\mathrm{AgW60}, \mathrm{Cu}$ & $\mathrm{Cu}(+)$ & & $\mathrm{AgW60}(+)$ \\
& $\mathrm{CuW60}, \mathrm{Cu}$ & $\mathrm{Cu}(+)$ & & $\mathrm{CuW60}(+)$ \\
\multirow{5}{*}{ Nitrogen } & $\mathrm{AgW60}, \mathrm{CuW} 60$ & & $\mathrm{AgW60}(+) \& \mathrm{CuW60}(+)$ & \\
& $\mathrm{AgW60}, \mathrm{Cu}$ & $\mathrm{Cu}(+)$ & $\mathrm{AgW60}(+)$ & \\
& $\mathrm{CuW60}, \mathrm{Cu}$ & & $\mathrm{CuW60}(+) \& \mathrm{Cu}(+)$ & \\
\hline \hline
\end{tabular}

Table 9. Three polar effects of anti-welding ability corresponding to asymmetrical mating.

\begin{tabular}{lllll}
\hline \hline Anode(+) & Cathode(-) & AgW60 & CuW60 & Cu \\
\cline { 1 - 3 } AgW60 & 0.05 & 0.78 & 0.36 \\
CuW60 & 1.00 & 9.84 & 0.88 \\
$\mathrm{Cu}$ & 5.45 & 10.25 & 3.29 \\
\hline \hline
\end{tabular}

Table 5. Average welding force $\bar{F}_{w 1}$ before the first welding in carbon dioxide [N].

\begin{tabular}{lllll}
\hline \hline Anode(+) & Cathode(-) & AgW60 & CuW60 & Cu \\
\cline { 1 - 4 } AgW60 & 0.33 & 3.20 & 0.17 \\
CuW60 & 7.25 & 19.40 & 1.23 \\
$\mathrm{Cu}$ & 3.25 & 8.36 & 0.75 \\
\hline \hline
\end{tabular}

Table 6. Average welding force $\bar{F}_{w 1}$ before the first welding in nitrogen [N].

but the welding resistance of the contacts is weakened. The reason may be that the number of operations is increased, the heat generation is increasing, leading to higher temperature. This will lead to a shorter time required for the contact material to melt, and thus, welding becomes likely to occur, resulting in the weaker welding resistance of the contacts.

The surface conditions directly affects the resistance of the contact [3]. Comparing Fig. 3 and Fig. 4 , the goodness of fit of the power function for the total average welding force and the average number of operations required for each weld is lower than the goodness of fit of the power function for the average welding force before the first welding and the average number of operations during the first welding. The reason may be: as the number of operations increases:

1. Under the action of arc heat, the lower melting point metals such as $\mathrm{Ag}$ and $\mathrm{Cu}$ in the two-phase pseudoalloys such as AgW60 and CuW60 flow under the action of electromagnetic force, and vaporize even splashing, so that the composition of the contact surface is no longer uniform, locally become a single-phase $\mathrm{Ag}, \mathrm{Cu}$ or $\mathrm{W}$ skeleton;

2. The pseudo-alloy containing tungsten forms a silver tungstate $\mathrm{Ag}_{2} \mathrm{WO}_{4}$ or tungsten oxide $\mathrm{WO}_{3}$ when it is working in carbon dioxide [4];

3. The surface of the contact is ablated by the arc to produce different degrees of defects.

\begin{tabular}{lllll}
\hline \hline Anode(+) & Cathode(-) & AgW60 & CuW60 & Cu \\
\cline { 1 - 4 } AgW60 & 0.07 & 0.12 & 0.04 \\
$\mathrm{CuW60}$ & 0.04 & 6.70 & 0.56 \\
$\mathrm{Cu}$ & 4.11 & 8.95 & 2.01 \\
\hline \hline
\end{tabular}

Table 7. Total average welding force $\bar{F}_{w}$ in carbon dioxide $[N]$.

\begin{tabular}{lllll}
\hline \hline Anode(+) & Cathode(-) & AgW60 & CuW60 & Cu \\
\cline { 1 - 3 } AgW60 & 0.17 & 1.75 & 0.30 \\
CuW60 & 2.94 & 9.45 & 0.68 \\
$\mathrm{Cu}$ & 2.42 & 7.24 & 0.34 \\
\hline \hline
\end{tabular}

Table 8. Total average welding force $\bar{F}_{w}$ in carbon dioxide $[N]$.

\section{Conclusion}

In this paper, the following conclusions can be drawn:

1. The welding resistance of the three materials in the symmetric pairing of carbon dioxide and nitrogen is ranked as $\mathrm{AgW} 60>\mathrm{Cu}>\mathrm{CuW} 60$. The "intermediate effect" occurs in the welding resistance of asymmetric pairing.

2. As the number of operations increases, the number of operations between each welding incidence is reduced, indicating weaker welding resistance.

3. As the number of operations increases, the average welding force of the contacts decreases.

4. The relationship between the average number of operations of the first welding of the contact and the average welding force before the first welding is approximately in an inverse proportional function. The relationship between the number of operations required for each occurrence of welding and the total average welding force is approximately in an inverse proportional function.

\section{References}

[1] Y. Shiba, Y. Morishita, S. Kaneko, S. Okabe, H. Mizoguchi, and S. Yanabu. Study of DC circuit breaker of $\mathrm{H}_{2}-\mathrm{N}_{2}$ mixture gas for high voltage. Ieee Transactions on Power $\&$ Energy, 174(2):9-17, 2008. doi:10.1541/ieejpes.128.1407. 
[2] X. Liu. A new mathematical model of dynamic welding for electric contacts. Transactions of China Electrotechnical Society, pages 81-84, 2002.

[3] F. Meng, J. Gao, Y. Wang, L. Qiao, and L. I. Rui. The study on process and properties of $\mathrm{Ag}-\mathrm{W}$ contact material. Materials Review, pages 321-324, 2006.

[4] F. Q. Dou, J. Zheng, Z. H. Ren, and L. Jian. Study on the arc-erosion properties of $\mathrm{AgW}$ and $\mathrm{AgSnO}_{2}$ used in the simulated conditions of automobile relays.

Electrical Engineering Materials, pages 6-9, 2009. 